\title{
Combining Immunotherapy with Multikinase Inhibitors: A Cautious New Promise
}

\begin{abstract}
Immune check point inhibitors have made a sea change in oncology practice in current times. These drugs have crossed the conventional boundaries of histology and organ of origin. Tumor agnostic approvals for mismatch repair deficient, microsatellite-instability (MSI)-H and recently tumor mutational burden-high solid tumors have been a giant leap. The Oncology community seems poised to embrace the concept of "immunotherapy for all." Recent studies have evaluated the manipulation of tumor-associated macrophages using multi-kinase inhibitors, to make even MSI low tumor responsive to checkpoint inhibitors. With accelerated food and drug administration approvals, the promise of this combo is palpable but definitely merits caution.
\end{abstract}

Keywords: Immune checkpoint inhibitors, lenvatinib, regorafenib

Immune checkpoint inhibitors (ICIs) have carved a niche for themselves in modern oncology practice. Crossing the barriers of histology and organ of origin, they now have tumor agnostic approval for any metastatic tumor that is mismatch repair (MMR) deficient, microsatellite- instability (MSI) high or has a high tumor mutational burden (TMB). While they work wonders for some patients, the effect is at best modest in others. Indeed, we are yet to find a sure-shot biomarker for these agents. Whenever any metastatic tumor progresses beyond 1-2 lines, and the treating oncologist feels pushed to the wall, running out of options; one explores this option. In reality, this option is scientifically applicable for only a select handful of patients.

For head neck squamous cancers, lung cancers without driver mutations, renal cell cancers, urothelial cancers, hepatocellular cancers, indications are broader and ICIs are applicable for the majority of metastatic cases as initial or subsequent treatment. But for adenocarcinomas of the gastrointestinal (GI) tract and gynecological malignancies, the indications are limited. MSI-H or MMRd tumors were traditionally eligible for ICI in the metastatic setting only after the failure of conventional

\footnotetext{
This is an open access journal, and articles are distributed under the terms of the Creative Commons Attribution-NonCommercial-ShareAlike 4.0 License, which allows others to remix, tweak, and build upon the work non-commercially, as long as appropriate credit is given and the new creations are licensed under the identical terms.
}

For reprints contact: WKHLRPMedknow_reprints@wolterskluwer.com first or second-line options. Recently, MSI-H colon cancers showed a doubling of progression free survival (PFS) with upfront (first-line) use of Pembrolizumab compared to chemotherapy and targeted therapy and it has received Food and Drug Administration (FDA) approval for the same. ${ }^{[1,2]}$ High TMB tumors, agnostic of its tissue, have also received approval for ICI therapy recently, but the oncology community has taken this approval with a pinch of salt. ${ }^{[3]}$ However, still then, in reality only a small fraction of these cancers; colorectal, gastric, pancreatic, biliary tract, ovarian, endometrial would be eligible for ICI therapy.

What if we can render these microsatellite-stable (MSS) or MMR proficient (MMRp) tumor immunologically hot and eligible for immunotherapy with ICIs? Will it open the Pandora's box and make all these tumors responsive to immune checkpoint inhibition? Definitely, but how's that possible?

Recently investigators have studied a novel strategy of combining multikinase inhibitors with immune-checkpoint inhibitors (such as Nivolumab and Pembrolizumab) to manipulate the tumor microenvironment and render MSS tumors responsive to ICIs. Results of some of these phase-1/2 studies have been recently published, reporting response rates of around $40 \%$ in several

\footnotetext{
How to cite this article: Pramanik R, Sharma A, Kumar A. Combining immunotherapy with multikinase inhibitors: A cautious new promise. Indian J Med Paediatr Oncol 2020;41:901-5.
}

\author{
Raja Pramanik, \\ Atul Sharma, \\ Akash Kumar \\ Department of Medical \\ Oncology, All India Institute of \\ Medical Sciences, New Delhi, \\ India
}

Submitted: 08-Jul-2020 Revised: 02-Aug-2020 Accepted: 05-Sep-2020 Published: $31-$ Dec-2020

Address for correspondence: Dr. Raja Pramanik, Department of Medical Oncology, Dr. B. R.A. Institute Rotary Cancer Hospital, All India Institute of Medical Sciences, New Delhi - 110 029, India.

E-mail: drrajapramanik@gmail. com

Access this article online

Website: www.ijmpo.org

DOI: 10.4103/ijmpo.ijmpo_326_20 Quick Response Code:

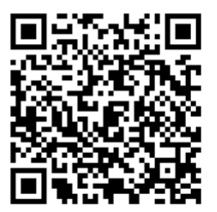


tumor types. These results are exciting and have given hope for the concept of "immunotherapy for all." These studies have given us very important insights into the mechanism of ICI resistance and simultaneously provide the proof of the concept that tumor-associated macrophages (TAMs) can indeed be modulated in favor of an anti-tumor immune response. An accelerated approval by the FDA to the combination of Lenvatinib and Pembrolizumab for metastatic endometrial carcinoma based on these early results, speaks for itself.

Combining a kinase inhibitor to immunotherapy is not new to oncology, for example, the ICI + tyrosine kinase inhibitors (TKI) combinations are the current standards of care in intermediate/poor-risk advanced renal cell carcinoma. ${ }^{[4,5]}$ The novelty, however, is evident in the mechanism of action. Sunitinib and Pembrolizumab tackle the two different active hallmark pathways (vascular endothelial growth factor [VEGF] pathway and immune synapses) each of which is known to provide a survival advantage to renal cell carcinoma. In contrast, the proposed mechanism of action of the combination of regorafenib with nivolumab is based on the theory that regorafenib would reduce T-regulatory cells and TAMs through suppression of VEGF receptor 2 and colony-stimulating factor 1 receptor. ${ }^{[6]}$ These are important immune-suppressive pathways that dampen the response to PD1/PDL1 axis inhibition. Lenvatinib has been shown to increase the anti-tumor activity of DD-1 by decreasing TAMs and enhancing the activation of the interferon signaling pathway in an in-vivo model. ${ }^{[7]}$ Thus, this dual combination can reverse the PD1/PDL1 axis inhibition converting an ICI resistant tumor into an ICI sensitive one, like a "magic wand."

Let us now focus on the three published studies in the last few months [Table 1]. Results of the REGONIVO, EPOC1603 study by Fukuoka et al. was published in the Journal of Clinical Oncology ${ }^{[6]}$ They treated 50 patients (25 each with gastric and colorectal cancer) with regorafenib and nivolumab in this phase $\mathrm{Ib}$ dose-expansion study, and all of them had progressed on least 2 lines of chemotherapy. They reported an objective tumor response in 20 patients $(40 \%)$, gastric cancer $(44 \%)$, and colorectal cancer (36\%). Median PFS was 5.6 months for gastric cancers and 7.9 months in patients with colorectal cancers, respectively. Rash (12\%), proteinuria (12\%), and palmar-plantar erythrodysesthesia $(10 \%)$ were reported as major side-effects. Fukuoka et al. concluded that the combination of Nivolumab and Regorafenib $80 \mathrm{mg}$ was safe and had encouraging antitumor activity, which merits further investigations in larger cohorts.

In another Japanese phase II trial, the EPOC1706 published in The Lancet Oncology, Kawazoe et al. administered the combination of lenvatinib and pembrolizumab as first-or second-line treatment for 29 patients of advanced gastric cancers. ${ }^{[8]}$ An objective response was observed in
$20(69 \%)$ patients, with similar responses in first line or second line settings $(71 \%$ and $67 \%$, respectively). At a median follow-up of 12.6 months, while median overall survival (OS) was not reached, the median PFS was 7.1 months. Interestingly, for the 19 patients who had a PD-L1 combined positive score (CPS) of $\geq 1$, the objective response rate (ORR) was $84 \%$ and PFS was 9.1 months. In contrast, ORR was $40 \%$ in 10 patients with CPS $<1$ with a PFS of 5.9 months. Patients with high TMB score (above the median of 10 ) had better ORR ( $82 \%$ versus $60 \%$ ) than a low TMB score. Hypertension (38\%) and proteinuria (17\%) were reported as the main Grade- 3 adverse events.

These two studies are important because they both report the first results of a potentially path-breaking dual combination regimen in an extremely challenging clinical situation for two common cancers. Treating metastatic colon and gastric cancers after 2 lines are extremely depressing in contemporary times. Most of us would either re-challenge a previous therapy or hunt for a targetable mutation by sequencing the tumor in this scenario, hoping against hope. A vast majority of these tumors are MMR proficient and hence not eligible for immune-oncology (IO) drugs. Thus, this scenario presents a real unmet need. Current standards of care in metastatic colorectal cancer (mCRC) include, FOLFOX \pm targeted therapy (Bevacizumab/epidermal growth factor receptor inhibitor) followed by FOLFIRI \pm targeted drugs as first- and second-line or vice-versa. Regorafenib and Trifluridine/Tipiracil are the FDA approved subsequent lines of therapy. IO drugs are indicated in approximately $2 \%-$ $4 \%$ of metastatic cases. ${ }^{[9]}$ Similarly, for metastatic stomach cancer, first-line $5 \mathrm{FU}+$ platins \pm (trastuzumab if human epidermal growth factor receptor 2 amplified) is followed by taxanes \pm ramucirumab in the second line. Nivolumab is approved in Japan as $2^{\text {nd }} /$ more line therapy based on the ATTRACTION 2 trial but is not yet FDA or European Medicines Agency approved. ${ }^{[10]}$ Pembrolizumab is FDA approved in the $3^{\text {rd }}$ line in those with CPS $\geq 1 .^{[11]}$ Again, around $10 \%-22 \%$ of all gastric tumors are MSI-H. ${ }^{[12]}$ Thus, for both these advanced cancers, this combination may apply to a huge proportion of hitherto ineligible patients. Although cross-trial comparisons are not encouraged, yet a glimpse of the synergistic effect of these combinations is evident from Table 2, which compares the single agent activities of these agents with the combination strategies. We can appreciate that for relapsed metastatic gastric cancers, single agent nivolumab or pembrolizumab has a meager $11 \%$ ORR, and regorafenib as a single agent has an ORR of $<1 \%$. However, the combination of nivolumab and regorafenib was able to produce an ORR of $44 \%$ and it reached $69 \%$ with Lenvatinib and pembrolizumab combination. Similarly, for mCRCs, ORR for regorafenib and nivolumab combination was 36\% in MSS tumors, while regorafenib alone could produce $1 \%-4 \%$ ORR. Notably, in MSI-H mCRC the ORR for nivolumab was $31 \%$. 


\begin{tabular}{|c|c|c|c|c|c|c|c|c|}
\hline $\begin{array}{l}\text { Study name, } \\
\text { author, journal }\end{array}$ & Combination & $\begin{array}{l}\text { Tumour } \\
\text { type }\end{array}$ & $\begin{array}{l}\text { Type of } \\
\text { study }\end{array}$ & $n$ & ORR & $\begin{array}{c}\text { PFS } \\
\text { (months) }\end{array}$ & OS & Comments \\
\hline \multirow{3}{*}{$\begin{array}{l}\text { REGONIVO/ } \\
\text { EPOCH 1603; } \\
\text { Fukuoka et al., JCO, } \\
\text { March } 2020^{[6]}\end{array}$} & \multirow{3}{*}{$\begin{array}{l}\text { Regorafenib + } \\
\text { nivolumab }\end{array}$} & \multirow{3}{*}{$\begin{array}{l}\mathrm{CRC}+ \\
\text { gastric } \mathrm{Ca} \\
\geq 2 \text { lines }\end{array}$} & \multirow[t]{3}{*}{ Phase $1 \mathrm{~b}$} & 50 & $36 \%(\mathrm{CRC})$ & \multirow{3}{*}{$\begin{array}{c}7.9 \\
(\mathrm{CRC}) \\
5.6 \\
\text { (gastric) }\end{array}$} & \multirow[t]{3}{*}{-} & $80 \mathrm{mg}$ RP2D for \\
\hline & & & & $25(\mathrm{CRC})$ & $44 \%$ (gastric) & & & regorafenib \\
\hline & & & & 25 (gastric) & & & & $\begin{array}{l}\text { Nivolumab=3 mg/kg/ } \\
2 \text { weeks }\end{array}$ \\
\hline \multirow{4}{*}{$\begin{array}{l}\text { EPOC1706; } \\
\text { Kawazoe et al., The } \\
\text { Lancet Oncology, } \\
\text { June } 2020^{[8]}\end{array}$} & \multirow{4}{*}{$\begin{array}{l}\text { Lenvatinib } \\
(20 \mathrm{mg} / \text { day })+ \\
\text { pembrolizumab } \\
(200 \mathrm{mg} \text { q } 3 \\
\text { weekly) }\end{array}$} & \multirow{4}{*}{$\begin{array}{l}\text { Gastric } \\
\text { cancer and } \\
\text { GEJ adeno } \\
\mathrm{Ca}\end{array}$} & \multirow[t]{4}{*}{ Phase II } & 29 & \multirow[t]{4}{*}{$69 \%$} & \multirow{4}{*}{$\begin{array}{c}7.1 \\
\text { months }\end{array}$} & \multirow{4}{*}{$\begin{array}{l}\text { Not } \\
\text { reached }\end{array}$} & 12.6 months follow up \\
\hline & & & & 14 ( $1^{\text {st }}$ line $)$ & & & & PDL-1 CPS $\geq 1 \%$ \\
\hline & & & & \multirow[t]{2}{*}{$15\left(2^{\text {nd }}\right.$ line $)$} & & & & $(\mathrm{ORR}=84 \%)$ \\
\hline & & & & & & & & $\mathrm{TMB}$ high $(\mathrm{ORR}=82 \%)$ \\
\hline \multirow{2}{*}{$\begin{array}{l}\text { Study } 111 / \\
\text { KEYNOTE-146 trial } \\
\text { (NCT02501096); } \\
\text { Makker } \text { et al., JCO, } \\
\text { Jan } 2020^{[17]}\end{array}$} & \multirow{2}{*}{$\begin{array}{l}\text { Lenvatinib } \\
(20 \mathrm{mg} / \text { day })+ \\
\text { pembrolizumab } \\
\text { ( } 200 \mathrm{mg} \text { q } 3 \\
\text { weekly) }\end{array}$} & \multirow{2}{*}{$\begin{array}{l}\text { Metastatic } \\
\text { endometrial } \\
\text { cancers }\end{array}$} & \multirow{2}{*}{$\begin{array}{l}\text { Phase } \\
\text {-Ib/II }\end{array}$} & 108 & ORR & \multirow[t]{2}{*}{7.4} & \multirow[t]{2}{*}{16.7} & \multirow[t]{2}{*}{18.7 months follow up } \\
\hline & & & & $\begin{array}{l}58 \text { patients } \\
\text { in interim } \\
\text { analysis }\end{array}$ & $\begin{array}{c}24 \text { weeks }=38.3 \% \\
\mathrm{CR}=10.6 \%\end{array}$ & & & \\
\hline
\end{tabular}

JCO -Journal of clinical oncology; CRC -Colorectal cancer; Ca -Cancer; GEJ - Gastro-oesophageal cancers; ORR - Overall response rate; PFS - Progression free survival; OS - Overall survival; RP2D - Recommended phase 2 dose; TMB - Tumour mutation burden; PDL1 - Programmed death ligand-1; CPS - Combined positive score

\begin{tabular}{|c|c|c|c|c|c|c|c|c|}
\hline Study name & Drug used & $\begin{array}{l}\text { Type of } \\
\text { study }\end{array}$ & $n$ & $\begin{array}{c}\text { ORR (CR + } \\
\text { PR) }\end{array}$ & DCR & $\begin{array}{l}\text { PFS (median } \\
\text { months); HR }\end{array}$ & $\begin{array}{c}\text { OS (median } \\
\text { months); HR }\end{array}$ & Comments \\
\hline \multicolumn{9}{|c|}{ Metastatic colorectal cancer (mCRC) } \\
\hline \multirow[t]{2}{*}{$\mathrm{CONCUR}^{[13]}$} & \multirow{2}{*}{$\begin{array}{l}\text { Regorafenib } \\
(\mathrm{R}) \text { versus } \\
\text { placebo }(\mathrm{P})\end{array}$} & \multirow[t]{2}{*}{ RCT } & $\mathrm{R}=136$ & $\mathrm{R}=4 \%$ & $\mathrm{R}=51 \%$ & $\mathrm{R}=3.2 \mathrm{~m}$ & $\mathrm{R}=8.8 \mathrm{~m}$ & \multirow[t]{2}{*}{ Asian population } \\
\hline & & & $\mathrm{P}=68$ & $\mathrm{P}=0 \%$ & $\mathrm{P}=7 \%$ & $\begin{array}{c}\mathrm{P}=1.7 \mathrm{~m} \\
\mathrm{HR}=0.31^{*}\end{array}$ & $\begin{array}{c}\mathrm{P}=6.3 \mathrm{~m} \\
\mathrm{HR}=0.55^{*}\end{array}$ & \\
\hline \multirow[t]{2}{*}{ CORRECT $^{[14]}$} & \multirow{2}{*}{$\begin{array}{l}\text { Regorafenib } \\
(\mathrm{R}) \text { versus } \\
\text { placebo }(\mathrm{P})\end{array}$} & \multirow[t]{2}{*}{ RCT } & $\mathrm{R}=505$ & $\mathrm{R}=1 \%$ & $\mathrm{R}=41 \%$ & $\mathrm{R}=1.9 \mathrm{~m}$ & $\mathrm{R}=6.4 \mathrm{~m}$ & \multirow[t]{2}{*}{ Western population } \\
\hline & & & $\mathrm{P}=255$ & $\mathrm{P}=0.4 \%$ & $\mathrm{P}=15 \%$ & $\begin{array}{c}\mathrm{P}=1.7 \mathrm{~m} \\
\mathrm{HR}=0.49^{*}\end{array}$ & $\begin{array}{c}\mathrm{P}=5.0 \mathrm{~m} \\
\mathrm{HR}=0.77^{*}\end{array}$ & \\
\hline CheckMate $142^{[15]}$ & Nivolumab & $\mathrm{Ph}-\mathrm{II}$ & 74 & $23 / 74=31 \%$ & $51 / 74=69 \%$ & & & dMMR/MSI-H only \\
\hline $\begin{array}{l}\text { REGONIVO/ } \\
\text { EPOCH } 1603^{[6]}\end{array}$ & $\begin{array}{l}\text { Regorafenib + } \\
\text { nivolumab }\end{array}$ & $\mathrm{Ph}-\mathrm{Ib}$ & 25 & $36 \%$ & & $7.9 \mathrm{~m}$ & & MSS tumours \\
\hline \multicolumn{9}{|c|}{ Metastatic Gastric cancer (mGC) } \\
\hline \multirow[t]{2}{*}{ ATTRACTION-2 ${ }^{[10]}$} & \multirow{2}{*}{$\begin{array}{l}\text { Nivolumab }(\mathrm{N}) \\
\text { Versus placebo } \\
\text { (P) }\end{array}$} & \multirow{2}{*}{ RCT } & \multirow[t]{2}{*}{$\mathrm{N}=493$} & $\mathrm{~N}=11 \%$ & $\mathrm{~N}=40 \%$ & \multirow[t]{2}{*}{--} & $\mathrm{N}=5.26 \mathrm{~m}$ & \multirow[t]{2}{*}{$\mathrm{mGC} \geq 2$ lines } \\
\hline & & & & $\mathrm{P}=0 \%$ & $\mathrm{P}=25 \%$ & & $\begin{array}{l}\mathrm{P}=4.14 \mathrm{~m} ; \\
\mathrm{HR}=0.63^{*}\end{array}$ & \\
\hline \multirow[t]{3}{*}{ KEYNOTE 059 $9^{[11]}$} & \multirow[t]{3}{*}{ Pembrolizumab } & \multirow[t]{3}{*}{$\mathrm{Ph}-\mathrm{II}$} & \multirow[t]{3}{*}{$\mathrm{N}=259$} & $11.6 \%$ & & & & \multirow[t]{3}{*}{$\mathrm{mGC}+\mathrm{GEJ}$} \\
\hline & & & & $15.5 \%(\mathrm{PDL} 1+)$ & & & & \\
\hline & & & & $6.4 \%$ (PDL1-) & & & & \\
\hline \multirow[t]{3}{*}{ INTEGRATE $^{[16]}$} & \multirow{3}{*}{$\begin{array}{l}\text { Regorafenib } \\
(\mathrm{R}) \text { versus } \\
\text { placebo }(\mathrm{P})\end{array}$} & \multirow{3}{*}{$\begin{array}{l}\mathrm{Ph}-\mathrm{II} \\
\mathrm{RCT}\end{array}$} & \multirow{3}{*}{$\mathrm{P}=50$} & \multirow{3}{*}{$\begin{array}{l}\mathrm{R}=3 / 97 \\
\mathrm{P}=1 / 50\end{array}$} & & $\mathrm{R}=2.6 \mathrm{~m}$ & $\mathrm{R}=5.8 \mathrm{~m}$ & \multirow[t]{3}{*}{ multinational } \\
\hline & & & & & & $\mathrm{P}=0.9 \mathrm{~m}$ & $\mathrm{P}=4.5 \mathrm{~m}$ & \\
\hline & & & & & & $\mathrm{HR}=0.40 *$ & $\mathrm{HR}=0.74^{\#}$ & \\
\hline $\begin{array}{l}\text { REGONIVO/ } \\
\text { EPOCH } 1603^{[6]}\end{array}$ & $\begin{array}{l}\text { Regorafenib + } \\
\text { nivolumab }\end{array}$ & $\mathrm{Ph}-\mathrm{Ib}$ & $\mathrm{N}=25$ & $44 \%$ & & $5.6 \mathrm{~m}$ & & Gastric $\mathrm{Ca} \geq 2$ lines \\
\hline \multirow[t]{3}{*}{ EPOC $1706^{[8]}$} & \multirow{3}{*}{$\begin{array}{l}\text { Lenvatinib }+ \\
\text { pembrolizumab }\end{array}$} & \multirow{3}{*}{$\mathrm{Ph}-\mathrm{II}$} & 29 & $69 \%$ & & \multirow[t]{3}{*}{$7.1 \mathrm{~m}$} & \multirow[t]{3}{*}{ NR } & \\
\hline & & & $14\left(1^{\text {st }}\right.$ line $)$ & & & & & \\
\hline & & & 15 ( $2^{\text {nd }}$ line $)$ & & & & & \\
\hline
\end{tabular}

${ }^{*} P<0.05,{ }^{\#} P>0.05 . \mathrm{M}-$ Months; Ph - Phase; ORR - Overall response rate (CR + PR); DCR - Disease control rate (CR + PR + SD $\geq 12$ weeks); CR - Complete response; PR - Partial response; PFS - Progression free survival; OS - Overall survival; NR - Not reported; HR - Hazard ratio; GEJ - Gastroesophageal junction; Ca-Cancer 
Many combinations of multikinase TKI and IO drugs are being evaluated for other MSS tumors as well. Lenvatinib + pembrolizumab has recently shown efficacy in advanced MSS endometrial cancers and has received an accelerated approval from the FDA for advanced endometrial cancers that is not MSI-high (MSI-H) or MMR deficient (dMMR). Notably, the doublet was simultaneously approved in the USA, Canada, and Australia after a collaborative review by FDA, Australian Therapeutic Goods Administration, and Health Canada. ${ }^{[18]}$ This review was done under FDA's Real-Time Oncology Review program, which has been developed to review application submissions more efficiently.

The approval was given on the basis of a multi-center, open-label, single arm, multi-cohort phase Ib/II Study 111/ KEYNOTE-146 trial (NCT02501096). ${ }^{[17]}$ In this study, 108 patients with previously treated metastatic endometrial cancer received $20 \mathrm{mg}$ lenvatinib orally once daily plus $200 \mathrm{mg}$ pembrolizumab given intravenously every 3 weeks. Of these patients, $87 \%$ of patients had non-MSI-H/dMMR tumors. The ORR at 24 weeks, was 38\%. At data cut off, around $7.4 \%$ patients had a complete response while the partial response rate was $31 \%$. Notably, $69 \%$ of responders had duration of response of at least 6 months. The most common grade 3 TRAEs were hypertension (34\%) and diarrhea $(8 \%)$.

While we do see these studies as light at the end of a dark tunnel, we must be extremely realistic in our expectations from these early-phase data. The response rates and survivals drop down in many regulatory phase-III studies when compared to their phase II data. Hence, these combinations should not be viewed as a panacea yet. It is noteworthy to mention the case of an IDO inhibiotor here. Although initial phase 1 and 2 studies of combined anti-PD-1/IDO (epacadostat) inhibitors (NCT02318277) were promising, surprisingly a phase III trial studying an epacodostat-pembrolizumab combination was abandoned as it failed to show a significant improvement in both PFS and OS. ${ }^{[19]}$

Nevertheless, while we palpate the potential of the above three combinations, we also identify some concerns and suggest ideas to these investigators when they plan their larger regulatory studies with these combinations. In the REGONIVO study, 98\% of the patients were ECOG-PS 0 , which is difficult to find in the real-world scenario in a $2^{\text {nd }} / 3^{\text {rd }}$ line setting. The most common grade 3 or more dose-limiting toxicities reported in this study were skin rash and all these responded to steroids. This likely means that they may also be nivolumab related. The $3+3$ design was planned for regorafenib dose determination only, keeping the nivolumab partner constant. There is no dose-response relationship in IO drugs. Recent studies suggest similar efficacy with lower doses or decreased frequency of nivolumab. ${ }^{[20-22]} \mathrm{We}$, therefore, suggest the use of lower nivolumab dosage also as an arm of any future planned study. This will also increase the reach and usage of this combo in the community practice. Given the case that generic regorafenib and lenvatinib is now available at an affordable price in many countries, these combos seem to have a future. It would also be interesting to see how this combo compares to single-agent Regorafenib in the $3^{\text {rd }}$ line setting in mCRC and how well this combo or the lenvatinib/ pembrolizumab combo compare to single-agent IO drugs in advanced gastric cancer. The authors do acknowledge the limitations of small sample size and rightly plan for larger studies. They must consider these issues while designing the comparator arms of future studies. Future studies must also be multicentric to improve the generalizability of the results.

Several ongoing trials are evaluating one of the multikinase inhibitors with ICI for the treatment of different tumors and we should expect interesting results in this field. Nivolumab in combination with cabozantinib is being studied in breast cancer, melanoma, carcinoids, nonclear cell renal cell cancers. ${ }^{[23]}$ The combination of regorafenib and pembrolizumab is being studied in colon cancers and hepatocellular cancers. ${ }^{[2]}$ Preclinical studies have established the pro-immunogenic effect of radiotherapy and its synergistic role with IO drugs. ${ }^{[25,26]}$ Radiotherapy is also being tried to augment the response to $\mathrm{IO}$ drugs (nivolumab and ipilimumab) in colon and pancreatic cancers, by converting "immunologically cold" tumors into "immunologically hot" ones. ${ }^{[27]}$

Immunotherapy seems poised to reach all tumors irrespective of the MSI boundaries. The oncology community must approach this "magic-wand" with utmost wisdom and caution. With the FDA accelerated approval, the combo is already in the prescriptions for endometrial cancers but for other GI tumors, it is at present best regarded as a "Cautious promise."

\section{Financial support and sponsorship}

Nil.

\section{Conflicts of interest}

There are no conflicts of interest.

\section{References}

1. Rates of Progression-Free Survival in MSI-H/dMMR Metastatic Colorectal Cancer Doubled by Pembrolizumab The ASCO Post. Available from: https://www.ascopost.com/issues/july10-2020-supplement-conference-highlights-asco20-virtual-sci entific-program/rates-of-progression-free-survivalin-msi-hdmmr-metastatic-colorectal-cancer-doubled-bypembrolizumab/. [Last accessed on $2020 \mathrm{Jul}$ 08].

2. Research $\mathrm{C}$ for DE and. FDA Approves Pembrolizumab for First-Line Treatment of MSI-H/dMMR Colorectal Cancer. FDA; 2020. Available from: https:/www.fda.gov/drugs/ drug-approvals-and-databases/fda-approves-pembrolizumab-fir st-line-treatment-msi-hdmmr-colorectal-cancer. [Last accessed on 2020 Jul 08]. 
3. Research $\mathrm{C}$ for DE and. FDA Approves Pembrolizumab for Adults and Children with TMB-H Solid Tumors. FDA; 2020. Available from: https://www.fda.gov/drugs/drug-approvals-and-databases/ fda-approves-pembrolizumab-adults-and-children-tmb-h-solidtumors. [Last accessed on $2020 \mathrm{Jul}$ 08].

4. Rini BI, Plimack ER, Stus V, Gafanov R, Hawkins R, Nosov D, et al. Pembrolizumab plus axitinib versus sunitinib for advanced renal-cell carcinoma. N Engl J Med 2019;380:1116-27.

5. Motzer RJ, Penkov K, Haanen J, Rini B, Albiges L, Campbell MT, et al. Avelumab plus axitinib versus sunitinib for advanced renal-cell carcinoma. N Engl J Med 2019;380:1103-15.

6. Fukuoka S, Hara H, Takahashi N, Kojima T, Kawazoe A, Asayama $\mathrm{M}$, et al. Regorafenib plus nivolumab in patients with advanced gastric or colorectal cancer: An open-label, dose-escalation, and dose-expansion phase Ib trial (REGONIVO, EPOC1603). J Clin Oncol 2020;38:2053-61.

7. Kato Y, Tabata K, Kimura T, Yachie-Kinoshita A, Ozawa Y, Yamada $\mathrm{K}$, et al. Lenvatinib plus anti-PD-1 antibody combination treatment activates $\mathrm{CD} 8+\mathrm{T}$ cells through reduction of tumor-associated macrophage and activation of the interferon pathway. PLoS One 2019;14:e0212513.

8. Kawazoe A, Fukuoka S, Nakamura Y, Kuboki Y, Mikamoto Y, Shima $\mathrm{H}$, et al. An open-label phase II study of lenvatinib plus pembrolizumab in patients with advanced gastric cancer (EPOC1706). J Clin Oncol 2020;38 Suppl 4:374-4.

9. Ganesh K, Stadler ZK, Cercek A, Mendelsohn RB, Shia J, Segal NH, et al. Immunotherapy in colorectal cancer: Rationale, challenges and potential. Nat Rev Gastroenterol Hepatol 2019;16:361-75.

10. Chen LT, Satoh T, Ryu MH, Chao Y, Kato K, Chung HC, et al. A phase 3 study of nivolumab in previously treated advanced gastric or gastroesophageal junction cancer (ATTRACTION-2): 2-year update data. Gastric Cancer 2020;23:510-9.

11. Fuchs CS, Doi T, Jang RW, Muro K, Satoh T, Machado M, et al. Safety and efficacy of pembrolizumab monotherapy in patients with previously treated advanced gastric and gastroesophageal Junction Cancer: Phase 2 Clinical KEYNOTE-059 Trial. JAMA Oncol 2018;4:e180013.

12. Ratti M, Lampis A, Hahne JC, Passalacqua R, Valeri N. Microsatellite instability in gastric cancer: Molecular bases, clinical perspectives, and new treatment approaches. Cell Mol Life Sci 2018;75:4151-62.

13. Li J, Qin S, Xu R, Yau TC, Ma B, Pan H, et al. Regorafenib plus best supportive care versus placebo plus best supportive care in Asian patients with previously treated metastatic colorectal cancer (CONCUR): A randomised, double-blind, placebo-controlled, phase 3 trial. Lancet Oncol 2015;16:619-29.

14. Grothey A, Van Cutsem E, Sobrero A, Siena S, Falcone A, Ychou M, et al. Regorafenib monotherapy for previously treated metastatic colorectal cancer (CORRECT): An international, multicentre, randomised, placebo-controlled, phase 3 trial. Lancet Lond Engl 2013;381:303-12.

15. Overman MJ, McDermott R, Leach JL, Lonardi S, Lenz HJ, Morse MA, et al. Nivolumab in patients with metastatic DNA mismatch repair-deficient or microsatellite instability-high colorectal cancer (CheckMate 142): An open-label, multicentre, phase 2 study. Lancet Oncol 2017;18:1182-91.

16. Pavlakis N, Sjoquist KM, Martin AJ, Tsobanis E, Yip S, Kang YK, et al. Regorafenib for the treatment of advanced gastric cancer (INTEGRATE): A multinational placebo-controlled phase II trial. J Clin Oncol 2016;34:2728-35.

17. Makker V, Rasco D, Vogelzang NJ, Brose MS, Cohn AL, Mier $\mathrm{J}$, et al. Lenvatinib plus pembrolizumab in patients with advanced endometrial cancer: An interim analysis of a multicentre, open-label, single-arm, phase 2 trial. Lancet Oncol 2019;20:711-8.

18. Research C for DE and. Simultaneous Review Decisions for Pembrolizumab Plus Lenvatinib in Australia, Canada andUS. FDA; 2019. Available from: https://www. fda.gov/drugs/resources-information-approved-drugs/ simultaneous-review-decisions-pembrolizumab-plus-lenvatinibaustralia- canada-and-us. [Last acessed on $2020 \mathrm{Jul}$ 08].

19. Khair DO, Bax HJ, Mele S, Crescioli S, Pellizzari G, Khiabany A, et al. Combining immune checkpoint inhibitors: Established and emerging targets and strategies to improve outcomes in melanoma. Front Immunol. 2019 Mar 19;10:453. doi: 10.3389/fimmu.2019.00453. PMID: 30941125; PMCID: PMC6435047.

20. Patil VM, Noronha V, Joshi A, Abhyankar A, Menon N, Banavali S, et al. Low doses in immunotherapy: Are they effective? Cancer Res Stat Treat 2019;2:54.

21. Yoo SH, Keam B, Kim M, Kim SH, Kim YJ, Kim TM, et al. Low-dose nivolumab can be effective in non-small cell lung cancer: Alternative option for financial toxicity. ESMO Open 2018;3:e00332.

22. Renner A, Burotto M, Rojas C. Immune checkpoint inhibitor dosing: Can we go lower without compromising clinical efficacy? J Glob Oncol. 2019 Jul;5:1-5. doi: 10.1200/JGO.19.00142. PMID: 31348737; PMCID: PMC6690659.

23. Search of: Cabozantinib Nivolumab List Results - Clinical Trials. Available from: https://clinicaltrials.gov/ct2/results?term= cabozantinib+nivolumab. [Last accessed on $2020 \mathrm{Jul}$ 08].

24. Search of: Pembrolizumab Regorafenib List Results ClinicalTrials. Available from: https://clinicaltrials.gov/ct2/result $\mathrm{s}$ ?cond $=\&$ term $=$ pembrolizumab + regorafenib \&cntry $=\&$ state $=\&$ cit $\mathrm{y}=\&$ dist. [Last accessed on $2020 \mathrm{Jul}$ 08].

25. Zeng J, See AP, Phallen J, Jackson CM, Belcaid Z, Ruzevick J, et al. Anti-PD-1 blockade and stereotactic radiation produce long-term survival in mice with intracranial gliomas. Int J Radiat Oncol Biol Phys 2013;86:343-9.

26. Deng L, Liang $\mathrm{H}$, Burnette $\mathrm{B}$, Beckett $\mathrm{M}$, Darga $\mathrm{T}$, Weichselbaum RR, et al. Irradiation and anti-PD-L1 treatment synergistically promote antitumor immunity in mice. J Clin Invest 2014;124:687-95.

27. Nivolumab and Ipilimumab and Radiation Therapy in MSS and MSI High Colorectal and Pancreatic Cancer Full Text View - Clinical Trials. Available from: https:/clinicaltrials.gov/ ct2/show/NCT03104439. [Last accessed on 2020 Aug 09]. 